\title{
MÉTODOS DE EXTRAÇÃo E DETERMINAÇÃO DO HERBICIDA GLIFOSATO: BREVE REVISÃo
}

\author{
Ozelito Possidônio de Amarante Júnior* e Teresa Cristina Rodrigues dos Santos \\ Departamento de Tecnologia Química, Universidade Federal do Maranhão, Av. dos Portugueses, s/n, 65080-040 São Luís - MA \\ Natilene Mesquita Brito e Maria Lúcia Ribeiro \\ Instituto de Química, Universidade Estadual Paulista, Rua Prof. Francisco Degni, s/n, 14800-900 Araraquara - SP
}

Recebido em 24/4/01; aceito em 24/9/01

\begin{abstract}
METHODS OF EXTRACTION AND DETERMINATION OF THE HERBICIDE GLYPHOSATE: COMPACT REVISION. This paper supplies a compact revision about the main extraction, clean-up and pre-concentration methods of the herbicide glyphosate for water and soil samples, as well as methods for its determination and quantification.
\end{abstract}

Keywords: glyphosate; extraction; determination.

\section{INTRODUÇÃO}

O desenvolvimento acelerado da agricultura tem levado ao aumento da necessidade do uso de pesticidas. Nos últimos anos, várias alternativas foram criadas no sentido de reduzir esta necessidade. Entretanto, algumas mudanças, tais como o advento de alimentos transgênicos, resistentes a algumas pragas, não resultaram na diminuição do uso de herbicidas, uma vez que não impedem o desenvolvimento de ervas daninhas no campo. Dentre os vários tipos de herbicidas, destacam-se aqueles de amplo espectro de ação, como é o caso dos não-seletivos. O glifosato [ $\mathrm{N}$-(fosfonometil)glicina] é classificado como herbicida não-seletivo, sistêmico e pós-emergente, citado como o mais vendido em todo o mundo, em diferentes formulações, produzidas por distintas companhias de pesticidas ${ }^{1,2}$. As estruturas do glifosato e de seu principal produto de degradação, o ácido aminometilfosfônico (AMPA), são apresentadas na Figura 1.<smiles>O=C(O)CNCP(=O)(O)O</smiles>

Glifosato<smiles>NCP(=O)(O)O</smiles>

AMPA
Figura 1. Estruturas dos compostos

Tamanho sucesso nas vendas do glifosato se deve à elevada eficiência na eliminação de ervas daninhas, com a vantagem adicional de ser de baixa toxicidade aos que o manipulam, à comunidade e ao ambiente. Apesar do herbicida ser citado como pouco tóxico, há evidências de efeitos deletérios em seres humanos devido à toxicidade ambiental, causando danos indiretos e também levando à resistência de algumas espécies de ervas que se adaptam após o uso prolongado do herbicida ${ }^{1}$.

Em função da ampla utilização do glifosato em todo o mundo, o desenvolvimento de métodos de extração e análise que permitam a detecção e quantificação do herbicida em amostras naturais são de suma importância. O objetivo deste trabalho é, portanto, discutir os

\footnotetext{
*e-mail: ozelito@terra.com.br
}

principais métodos para extração e análise do glifosato encontrados na literatura bem como para seu produto de degradação.

\section{MÉTODOS DE EXTRAÇÃO E PRÉ-CONCENTRAÇÃO}

Os métodos de extração de glifosato e AMPA em amostras de solo e água são apresentados na Tabela 1 .

\section{Extração em amostras de solo}

Devido à elevada polaridade do glifosato e sua tendência em formar espécies iônicas, a maioria dos procedimentos de extração do herbicida se baseiam em reações ácido-base, onde o composto, inicialmente ligado a espécies iônicas do solo através do grupo fosfato, passa, então, a interagir com os íons da solução ${ }^{2}$. Dessa forma, nos processos de extração são utilizadas, basicamente, soluções de bases fortes (por exemplo, $\mathrm{KOH}, \mathrm{NaOH}$ ), sais de bases fortes (como $\mathrm{KH}_{2} \mathrm{PO}_{4}$ ), bases fracas (tais como trietilamina, $\mathrm{NH}_{4} \mathrm{OH}$ ) ou ácidos fracos, seguindo-se, na maioria das vezes, de etapas de retenção/ eluição em resinas de troca iônica.

A eficiência no processo de extração do glifosato e AMPA está diretamente relacionada com o tipo de solo. Em geral, melhores recuperações são observadas para solos orgânicos, enquanto que para solos argilosos e minerais, devido à elevada competitividade pelos sítios iônicos do solo, a eficiência no processo de extração fica relativamente comprometida, resultando em menores recuperações ${ }^{3}$.

Vários procedimentos ${ }^{4}$ de extração para glifosato em amostras de solo foram testados, acompanhando a recuperação para solos tratados com substâncias radiomarcadas em intervalos de 14 dias (glifosato, ${ }^{14} \mathrm{C}$ ). Dos procedimentos testados, três apresentaram recuperações superiores a 73\%: (i) extração com solução de $\mathrm{NaOH} 0,1$ mol L-1; (ii) com solução de $\mathrm{H}_{3} \mathrm{PO}_{4} 0,35 \mathrm{~mol} \mathrm{~L}^{-1} \mathrm{e}$ (iii) com solução de $\mathrm{NH}_{4} \mathrm{OH} 0,5 \mathrm{~mol} \mathrm{~L}^{-1}$.

Em outro estudo 5 , foi feita extração com solução de KOH 0,6 mol L ${ }^{-1}$, resultando em recuperações entre $88-109 \%$ e $73-103 \%$ para glifosato e AMPA, respectivamente. Após a extração alcalina, o sobrenadante foi levado a pH entre 5,0 e 8,0 com solução de $\mathrm{HCl}$. Friestad e Broenstad ${ }^{6}$ utilizaram, igualmente, solução de KOH, realizando duas etapas de extração, seguidas de purificação com resina de troca aniônica na forma $\mathrm{OH}^{-}$. A eluição foi feita com $\mathrm{HCl} 1 \mathrm{~mol} \mathrm{~L}^{-1} \mathrm{e}$ as recuperações obtidas foram superiores a $60 \%$. Esta extração pode ser feita, ainda, com mistura de $\mathrm{NH}_{4} \mathrm{OH} 0,25 \mathrm{~mol} \mathrm{~L}^{-1}$ e $\mathrm{KH}_{2} \mathrm{PO}_{4} 0,1$ 
Tabela 1. Extração de glifosato e AMPA em amostras de água e solo

\begin{tabular}{|c|c|c|c|c|}
\hline Amostra & Extração & Purificação & Recuperação & Ref. \\
\hline \multirow[t]{8}{*}{ Solo } & $\mathrm{NH}_{4} \mathrm{OH} 0,5 \mathrm{~mol} \mathrm{~L}^{-1}$ & $\begin{array}{l}\text { Resina de troca aniônica seguida } \\
\text { de resina de troca catiônica }\end{array}$ & $\begin{array}{l}79 \% \text { (glifosato) } \\
68,5 \%(\text { AMPA })\end{array}$ & 3 \\
\hline & $\begin{array}{l}\mathrm{NaOH} 0,1 \mathrm{~mol} \mathrm{~L}^{-1} \\
\mathrm{H}_{3} \mathrm{PO}_{4} 0,35 \mathrm{~mol} \mathrm{~L}^{-1} \\
\mathrm{NH}_{4} \mathrm{OH} 0,5 \mathrm{~mol} \mathrm{~L}^{-1}\end{array}$ & & $73 \%$ (glifosato) & 4 \\
\hline & $\begin{array}{l}\mathrm{KOH} 0,6 \mathrm{~mol} \mathrm{~L}^{-1} \text { (neutralizando } \\
\text { o sobrenadante com } \mathrm{HCl} \text { ) }\end{array}$ & & $\begin{array}{l}88-109 \% \text { (glifosato) } \\
73-103 \% \text { (AMPA) }\end{array}$ & 5 \\
\hline & $\mathrm{KOH} 1 \mathrm{~mol} \mathrm{~L}^{-1}$ & Resina de troca aniônica $\left(\mathrm{OH}^{-}\right)$ & $>60 \%$ (glifosato e AMPA) & 6 \\
\hline & $\begin{array}{l}\mathrm{NH}_{4} \mathrm{OH} 0,25 \mathrm{~mol} \mathrm{~L}^{-1} \\
\mathrm{KH}_{2} \mathrm{PO}_{4} 0,1 \mathrm{~mol} \mathrm{~L}^{-1}\end{array}$ & Resina de troca catiônica $\left(\mathrm{H}^{+}\right)$ & $\begin{array}{l}90-100 \% \text { (glifosato) } \\
89-103 \% \text { (AMPA) } \\
\end{array}$ & 7 \\
\hline & Trietilamina $0,1 \mathrm{~mol} \mathrm{~L}^{-1}$ & $\begin{array}{l}\text { Resina de troca aniônica }\left(\mathrm{Cl}^{-}\right) \\
\text {seguida de troca catiônica }\left(\mathrm{H}^{+}\right)\end{array}$ & $88-104 \%$ (glifosato) & 8 \\
\hline & Trietilamina $0,1 \mathrm{~mol} \mathrm{~L}^{-1}$ & Resina Dowex 1-X8 & & 9 \\
\hline & $\begin{array}{l}\mathrm{KOH} 0,2 \mathrm{~mol} \mathrm{~L}^{-1} \\
\mathrm{KH}_{2} \mathrm{PO}_{4} 0,1 \mathrm{~mol} \mathrm{~L}^{-1} \\
\text { FMOC-Cl } 0,01 \mathrm{~mol} \mathrm{~L}^{-1}\end{array}$ & & & 10 \\
\hline \multirow[t]{10}{*}{$\overline{\text { Água }}$} & $\begin{array}{l}\text { Triclorometano (extração dos } \\
\text { interferentes e descarte da } \\
\text { fase orgânica) }\end{array}$ & $\begin{array}{l}\text { Resina de troca catiônica }\left(\mathrm{Fe}^{3+}\right) \\
\text { seguida de troca aniônica }\left(\mathrm{Cl}^{-}\right)\end{array}$ & $\begin{array}{l}80,9 \% \text { (glifosato) } \\
79,2 \% \text { (AMPA) }\end{array}$ & 12 \\
\hline & $\begin{array}{l}\text { Diclorometano (extração de } \\
\text { interferentes) }\end{array}$ & Resina de troca aniônica (AG 1-X8) & $\begin{array}{l}98,3 \% \text { (glifosato) } \\
86,3 \% \text { (AMPA) }\end{array}$ & 13 \\
\hline & $\begin{array}{l}\text { Diclorometano (extração de } \\
\text { interferentes) }\end{array}$ & Resina de troca aniônica $\left(\mathrm{OH}^{-}\right)$ & $\sim 85 \%$ (glifosato) & 14 \\
\hline & $\begin{array}{l}\text { Hipoclorito de aminas em hexano, } \\
\text { seguido de extração em } \mathrm{NaOH}\end{array}$ & & & 15 \\
\hline & Extração em Fase Sólida (EFS) & $\begin{array}{l}\text { Resina de troca catiônica }\left(\mathrm{Fe}^{3+}\right) \\
\text { seguida de troca aniônica }\left(\mathrm{Cl}^{-}\right)\end{array}$ & $>95 \%$ (glifosato) & 16 \\
\hline & EFS & Resina de troca aniônica $\left(\mathrm{OH}^{-}\right)$ & $67-81 \%$ (glifosato) & 6 \\
\hline & $\begin{array}{l}\text { Diclorometano/2-propanol } \\
\text { (após derivação, purificação e } \\
\text { acidificação) }\end{array}$ & & & 17 \\
\hline & EFS (após derivação) & & $>94 \%$ (glifosato e AMPA) & 18 \\
\hline & EFS & Resinas de troca catiônica e aniônica & & 21 \\
\hline & EFS & Resina de troca aniônica & $67-100 \%$ (glifosato) & 22 \\
\hline
\end{tabular}

mol L $\mathrm{L}^{-1}$, seguida de uma etapa de purificação com coluna contendo resina catiônica na forma $\mathrm{H}^{+}$. Foram obtidas recuperações entre 90$100 \%$ para o herbicida e $89-103 \%$ para seu metabólito ${ }^{7}$.

Thompson e colaboradores ${ }^{3}$ realizaram extração com $\mathrm{NH}_{4} \mathrm{OH}$ $0,5 \mathrm{~mol} \mathrm{~L}^{-1}$, seguida de purificação em duas etapas: a primeira utilizando resina de troca aniônica, eluída com $\mathrm{NH}_{4} \mathrm{HCO}_{3} 1 \mathrm{~mol} \mathrm{~L}^{-1}$, em que o bicarbonato foi removido por repetidas evaporações e redissoluções com água deionizada; a segunda etapa, efetuada em coluna com resina de troca catiônica, eluída com água, depois de evaporada e redissolvida em solução de $\mathrm{KH}_{2} \mathrm{PO}_{4}$ com $4 \%$ de metanol (pH 1,9). Foram obtidas recuperações em torno de 79 e $68,5 \%$ para glifosato e AMPA, respectivamente, para solos orgânicos, enquanto que em solos minerais obtiveram-se recuperações de 73 e $57 \%$ para estes compostos.

Glifosato foi também extraído de quatro tipos distintos de solos, utilizando solução de trietilamina $0,1 \mathrm{~mol} \mathrm{~L}^{-1}$, seguida de purifica- ção com resina de troca aniônica, na forma $\mathrm{Cl}^{-}$, e resina catiônica, na forma $\mathrm{H}^{+}$. Observou-se recuperações entre 88 e $104 \%$ para extrações realizadas logo após a fortificação do solo ${ }^{8}$. No entanto, para extrações feitas $13 \mathrm{~h}$ após a fortificação com o herbicida, considerável decréscimo nas recuperações foi observado. Deste estudo, pode-se concluir que a trietilamina é eficiente para a extração do herbicida solúvel ou fracamente ligado, não sendo eficaz quando o glifosato está fortemente adsorvido pelos constituintes do solo. Em outro estudo utilizando trietilamina ${ }^{9}$, foi realizada etapa de purificação com resina Dowex 1-X8 (50 a 100 mesh) e eluição com solução de $\mathrm{HCl}$ $0,1 \mathrm{~mol} \mathrm{~L}^{-1}$, obtendo-se resultados similares.

Miles e Moye ${ }^{10}$ apresentaram diferentes formas de extração do herbicida, de acordo com a característica do solo. Para solos argilosos e com altos teores de matéria orgânica, foi utilizada solução de $\mathrm{KOH}$ 0,2 mol L-1 (extrações por $15 \mathrm{~min}$ ). Para solos com baixos teores de argila e matéria orgânica, foi usada uma solução de $\mathrm{KH}_{2} \mathrm{PO}_{4}$ 
0,1 mol L ${ }^{-1}$. Ambos os métodos de extração são seguidos de centrifugação, filtração, derivação com cloroformato de 9-fluorenilmetoxicarbonil (FMOC-Cl) 0,01 mol L-1 em acetona, em meio tamponado com borato ( $\mathrm{pH}$ 9) e extração com acetato de etila ou éter.

\section{Extração em amostras de água}

Extrações de glifosato e seu principal metabólito em amostras de água são feitas, em geral, utilizando-se resinas de troca iônica ou, ainda, com prévia derivação e transformação em compostos apolares que podem ser, em função do agente derivatizante, mais facilmente extraídos. Em alguns estudos, em amostras de águas filtradas, é feito apenas o ajuste de $\mathrm{pH}$, seguido de evaporação.

Milles e colaboradores ${ }^{11}$ trabalharam com amostras de água filtradas em papel Whatman $\mathrm{n}^{\circ} 1$ (qualitativo), com adição de tampão fosfato $\left(\mathrm{KH}_{2} \mathrm{PO}_{4} 0,1 \mathrm{~mol} \mathrm{~L}^{-1}\right)$, em seguida concentrando as amostras diretamente em evaporador rotatório e procedendo nova filtração em filtro $0,2 \mu \mathrm{m}$. Foram obtidas recuperações entre 80 e $100 \%$, para AMPA, e 76 a $111 \%$, para glifosato.

Uma prática comum é efetuar a prévia extração dos possíveis interferentes, extraindo com solventes orgânicos. Cowell e colaboradores $^{12}$ utilizaram extração com triclorometano, purificando a fase aquosa em resina, na forma $\mathrm{Fe}^{3+}$. A eluição foi feita com $\mathrm{HCl} 6 \mathrm{~mol} \mathrm{~L}^{-1}$, seguida de tratamento com resina de troca aniônica, eluição com $\mathrm{HCl}$, evaporação até secura, retomando em água. Foram obtidas recuperações de $80,9 \%$ para glifosato e 79,2\% para AMPA.

Wigfield e Lanouette ${ }^{13}$ utilizaram partição, usando diclorometano, eliminando os compostos orgânicos de baixa polaridade pelo descarte da fase orgânica. A fase aquosa, contendo glifosato e AMPA, foi tratada com resina de troca aniônica AG 1-X8, eluída com citrato de potássio. Efetuada uma segunda extração em diclorometano, e descartando-se a fase orgânica, foi possível obter recuperações de 98,3\% para glifosato e 86,3\% para AMPA. No entanto, Abdullah e colaboradore $^{14}$, realizando procedimento semelhante, obtiveram recuperações em torno de $85 \%$. No caso, a fase aquosa, após extração dos interferentes apolares com diclorometano, foi purificada por passagem através de cartucho contendo $2 \mathrm{~mL}$ de resina, na forma $\mathrm{OH}^{-}$, lavagem com água e eluição com tampão citrato, pH 5.

Mistura de hexano e benzeno (2:3), na presença de solução de $\mathrm{MgCl}_{2} 1 \mathrm{~mol} \mathrm{~L}^{-1}$ foi usada na extração e análise de dichlorvos, inseticida organofosforado, sendo aproveitada a fase aquosa para a determinação de glifosato, extraído com mistura de hipoclorito de aminas primárias de cadeia normal, com 10 a 12 carbonos $\left(0,1 \mathrm{~mol} \mathrm{~L}^{-1}\right)$ em hexano ${ }^{15}$. Neste procedimento, uma nova etapa de extração foi realizada com $\mathrm{NaOH} 1 \mathrm{~mol} \mathrm{~L}^{-1}$, a fase aquosa sendo evaporada até secura, em presença de peróxido de hidrogênio a 30\%, e redissolvida em água.

Outros procedimentos de extração ${ }^{16}$ são baseados apenas na purificação com resina de troca iônica, sendo a amostra filtrada e tratada com resina de troca catiônica, na forma $\mathrm{Fe}^{3+}$, lavada com água e $\mathrm{HCl} 6 \mathrm{~mol} \mathrm{~L}^{-1}$, eluída com esta mesma solução ácida. O uso de resina catiônica dispensa a acidificação da amostra devido às propriedades zwiteriônicas do glifosato, que o mantém na forma catiônica mesmo em $\mathrm{pH}$ de águas naturais. $\mathrm{O}$ eluato, tratado com resina de troca aniônica, na forma $\mathrm{Cl}^{-}$, lavada em pequeno volume de $\mathrm{HCl} 6 \mathrm{~mol} \mathrm{~L}^{-1}$, foi eluído com a mesma solução ácida. Após evaporação até secura, o resíduo foi redissolvido em água. Recuperações superiores a 95\% foram obtidas.

Tratamento mais simples foi dado por Friestad e Broenstad ${ }^{6}$, que utilizaram apenas uma etapa de purificação em coluna de troca aniônica, na forma $\mathrm{OH}^{-}$, lavada com $\mathrm{KOH}$ e água, e eluída com $\mathrm{HCl}$ $1 \mathrm{~mol} \mathrm{~L}^{-1}$. O eluato foi tratado com carvão ativado, obtendo recuperações de 67 a $81 \%$.
Entre os métodos que fazem prévia derivação do glifosato, citase o de Gauch e colaboradores ${ }^{17}$ no qual foi utilizada água potável com tampão borato $0,5 \mathrm{~mol} \mathrm{~L}^{-1}$, derivando com FMOC-Cl em acetona e à temperatura ambiente, purificando os derivados com extração dos interferentes em diclorometano/2-propanol (3:1). A fase aquosa foi acidificada com ácido sulfúrico, e nova extração com solventes orgânicos foi realizada, descartando a fase aquosa. A solução orgânica contendo o derivado do glifosato foi seca por passagem em coluna de sulfato de sódio anidro, tendo seu $\mathrm{pH}$ corrigido com solução de amônia $25 \%$, evaporação a $60{ }^{\circ} \mathrm{C}$, lavagem do resíduo com diclorometano e redissolução em solução aquosa de metanol $50 \%$.

Vreeken e colaboradores ${ }^{18}$, utilizando o mesmo procedimento de derivação prévia com $\mathrm{FMOC}-\mathrm{Cl}$, em meio tamponado com tampão borato, a $37^{\circ} \mathrm{C}$, acrescentaram uma etapa automatizada de extração em fase sólida (EFS), usando adsorvente polimérico (PLRP-S). Recuperações obtidas para glifosato e AMPA foram superiores a 94\%.

Avramov e Vasileu ${ }^{19}$ evaporaram amostras de água até a secura, em atmosfera de $\mathrm{N}_{2}$ a $70{ }^{\circ} \mathrm{C}$, dissolvendo o resíduo em água e filtrando a solução resultante. Em seguida, glifosato foi derivado com cloreto de dansila na presença de $\mathrm{NaHCO}_{3}$ e acetona. A derivação foi feita sob abrigo de luz e à temperatura ambiente. Oppenhuizen e Cowell ${ }^{20}$ filtraram amostras de água em fibra de vidro $(1 \mu \mathrm{m})$, evaporaram até a secura e redissolveram em solução de tampão fosfato $0,005 \mathrm{~mol} \mathrm{~L}^{-1}$ (pH 2,1) e EDTA $0,03 \mathrm{~mol} \mathrm{~L}^{-1}$. A mistura foi posteriormente filtrada em membrana $0,45 \mathrm{~mm}$ e diretamente analisada por cromatografia líquida com derivação em pós-coluna, resultando em recuperações superiores a $82 \%$.

Procedimentos associando o tratamento com resinas de troca iônica e a derivação também têm sido desenvolvidos. Börjesson e Torstensson ${ }^{21}$, trataram amostras de água acidificadas com resina catiônica e, em seguida, resina aniônica, efetuando derivação com ácido trifluoroacético anidro (TFAA) e trifluoroetanol (TFE), retomando com acetato de etila, para posterior análise por cromatografia gasosa.

Sem e Baddoo $^{22}$, procederam a análise com água desaerada em banho de ultra-som, ajustando para pH 10 com solução de $\mathrm{NaOH}$. A amostra filtrada foi passada em resina de troca aniônica e eluída com ácido sulfúrico $2 \mathrm{~mol} \mathrm{~L}^{-1}$, em seguida, feita a derivação utilizando iodeto de potássio, ácido sulfâmico e ácido acético. Recuperações entre $67-100 \%$ foram obtidas.

\section{MÉTODOS DE ANÁLISE}

A molécula do glifosato apresenta elevada polaridade e ausência de cromóforo. Por estes motivos, a determinação do glifosato por cromatografia necessita de adaptações que permitam sua detecção. Tais adaptações incluem, basicamente, reações de derivação ou, ainda, alteração de alguma propriedade física que possa ser relacionada à quantidade de glifosato na amostra. Embora em algumas análises as alterações da estrutura da molécula do herbicida sejam feitas ainda durante as etapas de extração, na maioria das vezes, os procedimentos de derivação são feitos durante a análise propriamente dita, em etapas que antecedem a separação cromatográfica ou em reação pós-coluna.

\section{Análise por cromatografia líquida de alta eficiência (CLAE)}

A alta polaridade da molécula do glifosato e do seu metabólito tem levado ao desenvolvimento de muitos métodos de análise baseados em cromatografia líquida de alta eficiência (CLAE), de modo que a maioria das investigações relatadas na literatura para este herbicida se referem a esta técnica analítica. A dificuldade desta análise se refere à forma de detecção dos compostos, visto que ambos 
não possuem grupos cromóforos que possam ser detectados diretamente por detectores colorimétricos ou de UV, acima de $200 \mathrm{~nm}$. Faz-se necessário, portanto, o uso de reações de derivação, geralmente em pós-coluna, a fim de se obter um derivado que responda a estes detectores. Pode-se também, após derivação, utilizar detectores de fluorescência ${ }^{23}$. A Tabela 2 apresenta os métodos de determinação do Glifosato e seu produto de degradação por CLAE.

\section{Determinação por cromatografia líquida usando detecção por UV}

Em 1983, Burns ${ }^{24}$ publicou trabalho de determinação de glifosato por cromatografia líquida e detecção direta por UV, realizando um estudo colaborativo, no qual 20 laboratórios analisaram três pares de amostras combinadas, contendo alto teor do herbicida (41 a 96\%). As amostras foram dissolvidas na fase móvel, tampão fosfato $\mathrm{pH}$ 1,9 , contendo $4 \%$ de metanol, em um fluxo de $2,3 \mathrm{~mL} / \mathrm{min}$. Foi utilizada uma coluna de Partisil-10 SAX. A detecção foi realizada em $195 \mathrm{~nm}$, com coeficientes de variação de 0,88 a 1,7\%. Morlier e Tomkins ${ }^{25}$, utilizando o mesmo método em formulados do herbicida, obtiveram resultados similares. No entanto, segundo Morovjan e colaboradores $^{26}$, é possível obter limites de detecção de $10 \mu \mathrm{g} / \mathrm{L}$ utilizando coluna Dionex PAX-500 e fase móvel de tampão fosfato $\mathrm{pH}$ 3,15 e acetonitrila.

A sensibilidade do método pode ainda ser melhorada com uma etapa de derivação, obtendo-se um derivado que absorva em comprimento de onda maior. Powell e colaboradore ${ }^{27}$ derivaram o herbicida com metanol/fenil-isotiocianato/trietilamina/água (7:1:1:1), utilizando para a separação cromatográfica uma coluna recheada com material de $\mathrm{C} 18(4 \mu \mathrm{m})$ e eluindo com gradiente de acetonitrila em tampão acetato de sódio (pH 6,45) e acetonitrila/água/metanol. O comprimento de onda usado na detecção foi $254 \mathrm{~nm}$, resultando em adequada linearidade entre 0,05 e $10 \mathrm{nmol}$ do herbicida. As recuperações obtidas foram superiores a $77 \%$.

Huber e Calabrese ${ }^{28}$ derivaram o glifosato presente em amostras aquosas com $\mathrm{FMOC}-\mathrm{Cl}$, extraindo os derivados com acetato de etila, evaporando até a secura e, em seguida, retomando com trietoximetano, sob aquecimento. A análise cromatográfica foi feita em coluna recheada com $\mathrm{C} 18(5 \mu \mathrm{m})$ e a eluição com ácido trifluoroacético. A detecção foi realizada em comprimento de onda de $264 \mathrm{~nm}$.

\section{Determinação por cromatografia líquida com detecção colorimétrica}

Para determinação colorimétrica é necessária a derivação obtendo-se, assim, compostos coloridos. Uma alternativa é derivá-lo com 1-fluoro-2,4-dinitrobenzeno na presença de etanol e $\mathrm{NaBH}_{4}$. Os derivados são extraídos com acetato de etila, evaporados até secura, dissolvidos em água e depois separados em cartucho C18. Neste caso, a eluição foi feita com mistura de brometo de tetraetilamônio $0,02 \mathrm{~mol} \mathrm{~L}^{-1}$ e tampão fosfato de sódio $\mathrm{pH} 3,2$. A detecção foi realizada em $405 \mathrm{~nm}$, obtendo-se limite de detecção de $0,05 \mu \mathrm{g} / \mathrm{g}^{29}$.

Thompson e colaboradores ${ }^{3}$ procederam a derivação em pós-coluna com ninhidrina, a $100{ }^{\circ} \mathrm{C}$ e detecção em $570 \mathrm{~nm}$. Os limites de detecção obtidos foram em torno de $0,03 \mu \mathrm{g} / \mathrm{g}$ para glifosato e $0,01 \mu \mathrm{g} / \mathrm{g}$ para AMPA. No entanto, melhor sensibilidade para glifosato poderia, ainda, ser obtida se fosse utilizada temperatura mais elevada durante a reação em pós-coluna. A separação cromatográfica foi feita em coluna catiônica, a $50{ }^{\circ} \mathrm{C}$, eluindo com tampão fosfato em $\mathrm{pH} 1,9$, contendo $4 \%$ de metanol.

Observou-se, no entanto, que as recuperações obtidas no método de derivação com ninhidrina variavam de acordo com o tipo de solo em estudo. Contrariamente ao citado na literatura, em solos orgânicos, geralmente, as recuperações para glifosato foram superio- res às obtidas em solos minerais. Concentrações de glifosato e AMPA entre 0,5-30 ng/mL e 0,125-7,5 ng/L puderam ser determinadas.

\section{Determinação por cromatografia líquida com detector de fluorescência}

Certamente a determinação por fluorescência é o método de detecção mais aplicado na análise cromatográfica de glifosato devido à maior sensibilidade e seletividade deste tipo de detecção, se comparada com a detecção por absorção no UV-VIS. Desta forma, glifosato e seu produto de degradação podem ser devidamente transformados em compostos fluorescentes através de reações de derivação específicas. Dentre os reagentes mais utilizados estão o $o$ ftalaldeído (OPA), o FMOC-Cl e o cloreto de $p$-toluenosulfonila.

A derivação com OPA é bastante citada na literatura. Neste caso, glifosato é previamente oxidado a glicina, em meio alcalino e em temperaturas superiores a $40^{\circ} \mathrm{C}$. Para formação de um composto fluorescente mais estável, a reação é feita em presença de mercaptoetanol ${ }^{4}$.

Tuinstra e Kienhuis ${ }^{30}$ utilizaram reação em pós-coluna, oxidando o glifosato com hipoclorito em $\mathrm{pH} 9,1$, reagindo, em seguida, com OPA e 2-mercaptoetanol em metanol ( $\mathrm{pH}$ 9,2). A separação cromatográfica de glifosato e AMPA foi realizada em coluna Ionosphere A, eluídos com $\mathrm{KH}_{2} \mathrm{PO}_{4}$ em pH 2,1, sendo medidos em $400 \mathrm{~nm}$, com excitação em $360 \mathrm{~nm}$. Recuperações em torno de $80 \%$ foram obtidas. Em outro estudo ${ }^{12}$ a coluna cromatográfica foi substituída por coluna catiônica, operada a $50{ }^{\circ} \mathrm{C}$, eluída com $\mathrm{KH}_{2} \mathrm{PO}_{4}(\mathrm{pH}$ 1, 9) em metanol, usando as mesmas reações em pós-coluna, porém utilizando excitação em $340 \mathrm{~nm}$ e emissão em $455 \mathrm{~nm}$. Recuperações similares às anteriormente citadas foram obtidas para glifosato e AMPA, com limite de detecção de 0,05 a $5 \mu \mathrm{g} / \mathrm{g}$. Abdullah e colaboradores ${ }^{14}$ obtiveram recuperações pouco superiores $(85 \%)$ substituindo a coluna por uma de fase reversa, eluindo com tampão $\mathrm{KH}_{2} \mathrm{PO}_{4}$ em pH 2,1. A detecção foi realizada nos mesmos comprimentos de onda já citados.

Reupert e Fuchs ${ }^{31}$ obtiveram recuperações superiores a 95\% por substituição da coluna por uma específica para glifosato, baseada em troca catiônica, na forma de $\mathrm{K}^{+}$, operada a $55^{\circ} \mathrm{C}$, e também eluída com tampão fosfato ( $\mathrm{pH} 2,05)$. A oxidação prévia foi feita com hipoclorito de sódio em $\mathrm{pH} 11,9$ em temperatura de $40^{\circ} \mathrm{C}$ e a derivação ocorreu com OPA e NN-dimetil-2-mercaptoetilamina em pH 10,6 e à temperatura ambiente. $\mathrm{O}$ limite de detecção citado foi de $0,5 \mu \mathrm{g} / \mathrm{L}$, com excitação em $340 \mathrm{~nm}$ e medida de fluorescência em $440 \mathrm{~nm}$.

Outra derivação ${ }^{19}$ pode ser feita com cloreto de dansila em reação por $4 \mathrm{~h}$, sob abrigo da luz e temperatura ambiente, utilizando tampão carbonato $0,05 \mathrm{~mol} \mathrm{~L}^{-1}$. A determinação, feita com $\lambda_{\text {exc }}=340$ $\mathrm{nm}$ e $\lambda_{\mathrm{em}}=550 \mathrm{~nm}$, apresentou limites de detecção de $20 \mathrm{ng}$ para glifosato e 2 ng para AMPA. O método apresentou boa linearidade entre 0,2 e $1 \mu \mathrm{g}$ e entre 0,02 e $0,5 \mu \mathrm{g}$ para o herbicida e seu produto de degradação, respectivamente.

A etapa de derivação do glifosato pode ser efetuada de forma direta em amostras de solo com FMOC-Cl em acetona por $20 \mathrm{~min}^{10}$. Os derivados obtidos foram posteriormente extraídos em acetato de etila ou éter, realizando separação cromatográfica em coluna de $\mathrm{NH}_{2}$ e eluindo com tampão $\mathrm{KH}_{2} \mathrm{PO}_{4}(\mathrm{pH}$ 6) e acetonitrila. A detecção foi realizada com $\lambda_{\text {exc }}=270 \mathrm{~nm}$ e $\lambda_{\text {em }}=315 \mathrm{~nm}$. Ainda utilizando FMOC$\mathrm{Cl}$ como reagente de derivação, procedendo a reação por $30 \mathrm{~min}$, Sancho e colaboradores ${ }^{5}$ testaram três separações cromatográficas. A primeira foi realizada com coluna $\mathrm{C} 18$, eluindo com acetonitrila/ tampão fosfato $\mathrm{pH}$ 6,3; a segunda foi feita em coluna de menor comprimento, porém com mesmo material, eluindo com acetonitrila/tampão fosfato $\mathrm{pH} 5,7$ e a terceira separação foi feita com coluna $\mathrm{NH}_{2}$, eluída com acetonitrila/tampão fosfato $\mathrm{pH}$ 5,7. A detecção foi reali- 
Tabela 2. Determinação de glifosato e AMPA por CLAE

\begin{tabular}{|c|c|c|c|c|}
\hline Amostra & Derivação & Coluna e eluição & Detecção & Ref. \\
\hline \multirow[t]{2}{*}{ Formulados } & & $\begin{array}{l}\text { FM: tampão fosfato (pH 1,9) } \\
\text { Coluna: Partisil-10 SAX }\end{array}$ & UV (195 nm) & 24 \\
\hline & & $\begin{array}{l}\text { FM: tampão fosfato (pH 1,9) } \\
\text { Coluna: Partisil-10 SAX }\end{array}$ & UV (195 nm) & 25 \\
\hline \multirow[t]{2}{*}{ Soluções padrão } & & $\begin{array}{l}\text { FM: tampão fosfato (pH 3,15) } \\
\text { e acetonitrila Coluna: Dionex } \\
\text { PAX-500 }\end{array}$ & UV (195 nm) & 26 \\
\hline & $\begin{array}{l}\text { Metanol/fenilisocianato/trietilamina/ } \\
\text { água }(7: 1: 1: 1)\end{array}$ & $\begin{array}{l}\text { FM: gradiente de acetonitrila em } \\
\text { em tampão acetato e } \\
\text { acetonitrila/água/metanol } \\
\text { Coluna: C18 }\end{array}$ & UV (254 nm) & 27 \\
\hline Água & FMOC-Cl & $\begin{array}{l}\text { FM: ácido trifluoroacético } \\
\text { Coluna: C18 }\end{array}$ & UV (264 nm) & 28 \\
\hline \multirow[t]{2}{*}{ Solo } & $\begin{array}{l}\text { 1-fluoro-2,4-dinitrobenzeno/ } \\
\text { etanol/ } \mathrm{NaBH}_{4}\end{array}$ & $\begin{array}{l}\text { FM: brometo de tetraetilamônio } \\
\text { e tampão fosfato (pH 3,2) } \\
\text { Coluna: } \mathrm{C} 18\end{array}$ & VIS (405 nm) & 29 \\
\hline & ninhidrina & $\begin{array}{l}\text { FM: tampão fosfato }(\mathrm{pH} 1,9) \\
\text { Coluna: catiônica }\end{array}$ & VIS (570 nm) & 3 \\
\hline Vegetais & $\begin{array}{l}\text { Hipoclorito, OPA, mercaptoetanol } \\
\text { (pós-coluna) }\end{array}$ & $\begin{array}{l}\text { FM: } \mathrm{KH}_{2} \mathrm{PO}_{4}(\mathrm{pH} 2,1) \\
\text { Coluna: Ionosphere A }\end{array}$ & $\begin{array}{l}\text { Fluorescência } \\
\lambda_{\mathrm{exc}}=360 \mathrm{~nm} \\
\lambda_{\mathrm{em}}=400 \mathrm{~nm}\end{array}$ & 30 \\
\hline \multirow[t]{4}{*}{ Água } & $\begin{array}{l}\text { Hipoclorito, OPA, mercaptoetanol } \\
\text { (pós-coluna) }\end{array}$ & $\begin{array}{l}\text { FM: } \mathrm{KH}_{2} \mathrm{PO}_{4}(\mathrm{pH} 1,9) \\
\text { Coluna: catiônica }\end{array}$ & $\begin{array}{l}\text { Fluorescência } \\
\lambda_{\text {exc }}=340 \mathrm{~nm} \\
\lambda_{\mathrm{em}}=455 \mathrm{~nm}\end{array}$ & 12 \\
\hline & $\begin{array}{l}\text { Hipoclorito, OPA, mercaptoetanol } \\
\text { (pós-coluna) }\end{array}$ & $\begin{array}{l}\text { FM: } \mathrm{KH}_{2} \mathrm{PO}_{4}(\mathrm{pH} 2,1) \\
\text { Coluna: } \mathrm{C} 18\end{array}$ & $\begin{array}{l}\text { Fluorescência } \\
\lambda_{\text {exc }}=340 \mathrm{~nm} \\
\lambda_{\mathrm{em}}=455 \mathrm{~nm}\end{array}$ & 14 \\
\hline & $\begin{array}{l}\text { Hipoclorito, OPA, N,N-dimetil-2- } \\
\text { mercaptoetilamina (pós-coluna) }\end{array}$ & $\begin{array}{l}\text { FM: } \mathrm{KH}_{2} \mathrm{PO}_{4}(\mathrm{pH} \text { 2,05) } \\
\text { Coluna: específica para } \\
\text { glifosato (troca catiônica, } \mathrm{K}^{+} \text {) }\end{array}$ & $\begin{array}{l}\text { Fluorescência } \\
\lambda_{\text {exc }}=340 \mathrm{~nm} \\
\lambda_{\mathrm{em}}^{\mathrm{e}}=440 \mathrm{~nm}\end{array}$ & 31 \\
\hline & Cloreto de dansila & & $\begin{array}{l}\text { Fluorescência } \\
\lambda_{\mathrm{exc}}=340 \mathrm{~nm} \\
\lambda_{\mathrm{em}}^{\mathrm{em}}=550 \mathrm{~nm}\end{array}$ & 19 \\
\hline \multirow[t]{2}{*}{ Solo } & FMOC-Cl & $\begin{array}{l}\text { FM: } \mathrm{KH}_{2} \mathrm{PO}_{4}(\mathrm{pH} \mathrm{6}) \mathrm{e} \\
\text { acetonitrila Coluna: } \mathrm{NH}_{2}\end{array}$ & $\begin{array}{l}\text { Fluorescência } \\
\lambda_{\text {exc }}=270 \mathrm{~nm} \\
\lambda_{\mathrm{em}}=315 \mathrm{~nm}\end{array}$ & 10 \\
\hline & FMOC-Cl (pós-coluna) & $\begin{array}{l}\text { FM: } \mathrm{KH}_{2} \mathrm{PO}_{4}(\mathrm{pH} \mathrm{6,3}) \mathrm{e} \\
\text { acetonitrila - Coluna: } \mathrm{C} 18 \\
\text { FM: } \mathrm{KH}_{2} \mathrm{PO}_{4}(\mathrm{pH} \mathrm{5,7)} \mathrm{e} \\
\text { acetonitrila - Coluna: } \mathrm{C} 18 \\
\text { FM: } \mathrm{KH}_{2} \mathrm{PO}_{4}(\mathrm{pH} \mathrm{6,3}) \mathrm{e} \\
\text { acetonitrila - Coluna: } \mathrm{NH}_{2}\end{array}$ & $\begin{array}{l}\text { Fluorescência } \\
\lambda_{\mathrm{exc}}=340 \mathrm{~nm} \\
\lambda_{\mathrm{em}}=440 \mathrm{~nm}\end{array}$ & 5 \\
\hline \multirow[t]{2}{*}{ Soluções padrão } & $p$-tolueno-sulfonila & $\begin{array}{l}\mathrm{FM}: \mathrm{KH}_{2} \mathrm{PO}_{4}(\mathrm{pH} 2,3) \mathrm{e} \\
\text { acetonitrila Coluna: } \mathrm{C} 18\end{array}$ & $\begin{array}{l}\text { Fluorescência } \\
\lambda_{\mathrm{em}}=240 \mathrm{~nm}\end{array}$ & 32 \\
\hline & Alumínio e morina (pós-coluna) & $\begin{array}{l}\text { FM: solução de nitrato de } \\
\text { sódio - Coluna: PRP-X100 } \\
\text { FM: solução de ácido nítrico - } \\
\text { Coluna: PRP-X400 }\end{array}$ & Fluorescência & 33 \\
\hline \multirow[t]{5}{*}{ Água } & FMOC-Cl & Coluna: C18 & EM/EM & 18 \\
\hline & & $\begin{array}{l}\text { FM: solução de } \mathrm{Na}_{2} \mathrm{CO}_{3} \text { e } \\
\mathrm{NaHCO}_{3}(\mathrm{pH} 10,30 ; \text { isocrática) } \\
\text { ou de } \mathrm{Na}_{2} \mathrm{CO}_{3} \text { e } \mathrm{NaHCO}_{3} \\
\text { (pH 10,30) (eluente A) e os } \\
\text { mesmos sais em pH 10,08 } \\
\text { (gradiente) } \\
\text { Coluna: troca aniônica }\end{array}$ & EM & 34 \\
\hline & $\operatorname{Ru}\left(\text { tris- }\left(2,2^{\prime} \text {-bipiridil }\right)\right)_{3}{ }^{2+}($ pós-coluna $)$ & $\begin{array}{l}\text { FM: solução de ácido nítrico } \\
\text { (pH 2,5) - Coluna: troca catiônica }\end{array}$ & Quimiluminescência & 35 \\
\hline & $\operatorname{Ru}\left(\text { tris- }\left(2,2^{\prime} \text {-bipiridil }\right)\right)_{3}{ }^{2+}($ pós-coluna $)$ & $\begin{array}{l}\text { FM: tampão fosfato (pH 9) - } \\
\text { Coluna: troca aniônica } \\
\text { FM: solução de Ru(tris-(2,2'- } \\
\text { bipiridil) })_{3}^{2+} \text { em acetonitrila/tampão } \\
\text { fosfato- Coluna: troca aniônica }\end{array}$ & & \\
\hline & $\begin{array}{l}\text { Iodeto de potássio, ácido sulfâmico } \\
\text { e ácido acético (pós-coluna) }\end{array}$ & $\begin{array}{l}\text { FM: solução de ácido sulfúrico } \\
\text { Coluna: troca aniônica }\end{array}$ & Quimiluminescência & 22 \\
\hline
\end{tabular}


zada com $\lambda_{\text {exc }}=340 \mathrm{~nm}$ e $\lambda_{\text {em }}=440 \mathrm{~nm}$, apresentando recuperações de 88 a $109 \%$ para glifosato e 73 a $103 \%$ para AMPA.

Kawai e colaboradores ${ }^{32}$ utilizaram $p$-tolueno-sulfonila em acetonitrila e tampão fosfato ( $\mathrm{pH} 11)$ para derivação prévia do glifosato, a $50{ }^{\circ} \mathrm{C}$ por $5 \mathrm{~min}$, seguida de análise cromatográfica em coluna $\mathrm{C} 18$, eluída com tampão fosfato em $\mathrm{pH}$ 2,3 e acetonitrila. A detecção do composto fluorescente foi feita em $240 \mathrm{~nm}$.

Outra alternativa de análise do glifosato foi feita a partir de composto fluorescente formado entre alumínio e morina, testando a separação com duas colunas cromatográficas, PRP-X100, eluída com nitrato de sódio, e PRP-X400, eluída com ácido nítrico ${ }^{33}$. A reação de derivação foi feita em pós-coluna, em meio de tampão acetato, em $80 \%$ de etanol, operada a $55^{\circ} \mathrm{C}$. A detecção foi efetuada por fluorescência, sendo obtido limite de detecção de $14 \mathrm{ng}$.

\section{Determinação por cromatografia líquida acoplada à espectrometria de massas}

Segundo Bauer e colaboradores ${ }^{34}$, a determinação cromatográfica de glifosato com detecção por espectrometria de massas (EM) sem derivação não é suficientemente eficiente. Vreeken e colaboradores ${ }^{18}$ realizaram derivação com $\mathrm{FMOC}-\mathrm{Cl}$, seguido de separação cromatográfica utilizando coluna C18. Foi utilizado CLAE/EM/EM com ionização por "eletrospray", monitorando-se três fragmentos para o herbicida e seu produto de degradação, melhorando a seletividade do método. Bauer e colaboradores ${ }^{34}$, substituíram a coluna C18 por uma de troca aniônica, testando duas eluições: a primeira isocrática com mistura de carbonato e bicarbonato de sódio em pH 10,30 e outra em gradiente de eluição onde o eluente 'A' era a mistura já citada e o eluente ' $\mathrm{B}$ ' uma mistura dos mesmos sais, em pH 10,08. O uso de gradiente de eluição resultou em melhores cromatogramas, aumentando a sensibilidade do método. Glifosato e AMPA foram determinados por fragmentos característicos, $\mathrm{m} / \mathrm{z} 168$ e $m / z, 110$, respectivamente.

\section{Determinação por cromatografia líquida com quimiluminescência}

A análise por cromatografia líquida usando detecção por quimiluminescência foi testada em três metodologias: a primeira utilizando coluna de troca catiônica, eluída com ácido nítrico em $\mathrm{pH}$ 2,5 acoplada a uma pós-coluna com adição de $\mathrm{Ru}$ (tris-(2,2' bipiridil) $)_{3}{ }_{3}^{2+}$; a segunda com coluna de troca aniônica, eluída com tampão fosfato em $\mathrm{pH} 9$, acoplada a pós-coluna com adição de Ru(tris$(2,2$ '-bipiridil $){ }_{3}{ }^{2+}$ em tampão fosfato; e a terceira metodologia utilizando a mesma coluna de troca aniônica citada anteriormente, mas eluída com Ru(tris-(2,2'-bipiridil) $)_{3}{ }^{2+} \mathrm{em}$ acetonitrila/tampão fosfato em pH 9,8 (1:9), sem necessidade de pós-coluna ${ }^{35}$. Todas as três metodologias utilizaram detecção por quimiluminescência, usando cela de 2,5 $\mu \mathrm{L}$, com eletrodo de trabalho de carbono mantido a 1,25 $\mathrm{V}$ e eletrodo de referência de $\mathrm{Ag} / \mathrm{AgCl}$. Obteve-se limite de detecção de $0,01 \mu \mathrm{mol} \mathrm{L}{ }^{-1}$.

Sem e Baddoo $^{22}$ utilizaram coluna cromatográfica de troca aniônica, eluída com ácido sulfúrico, e pós-coluna mergulhada em água a $70^{\circ} \mathrm{C}$, reagindo-se com iodeto de potássio, ácido sulfâmico e ácido acético. $\mathrm{O}$ monóxido de nitrogênio gerado foi arrastado por Hélio para a cela, obtendo-se recuperações de 67 a 100\%.

\section{Análise por cromatografia em camada delgada (CCD)}

Embora pouco aplicável a amostras ambientais devido à baixa sensibilidade, Bunyatyan e Gevorgyan ${ }^{36}$ determinaram glifosato quantitativamente por cromatografia em camada delgada (CCD), usando placas de Fixiona 50-X8 (forma $\mathrm{Na}^{+}$), operadas a $50{ }^{\circ} \mathrm{C}$ e utilizando solução de $\mathrm{Ba}_{2} \mathrm{~B}_{4} \mathrm{O}_{7}$ como fase móvel. A detecção foi realizada com ninhidrina $1 \%$ em acetona e acetato de cádmio em solução aquosa de anidrido acético em meio ácido (5:1). Segundo os autores, a relação entre a área da mancha e a concentração foi linear de 0,5 a $30 \mu \mathrm{g}$ e 0,1 a $20 \mu \mathrm{g}$ de glifosato e AMPA, respectivamente. Foram usados extratos aquosos das amostras, com limites de detecção de $0,05 \mathrm{mg} / \mathrm{Kg}$ para amostras de água e solo.

\section{Análise por cromatografia gasosa (CG)}

A técnica de cromatografia gasosa é a segunda mais amplamente empregada para determinação de glifosato. Para a determinação do herbicida por CG, faz-se necessária um prévia derivação para obtenção de composto volátil, porém, esta técnica apresenta a vantagem da ótima sensibilidade. Os métodos de análise deste herbicida e seu produto de degradação por CG são mostrados na Tabela 3.

\section{Determinação por cromatografia gasosa acoplada à espectrometria de massas}

Tsunoda $^{37}$ determinou glifosato por CG após derivação com Nmetil-N-(t-butildimetilsilil)trifluoroacetamida em DMF, obtendo-se, assim, um composto volátil. A análise cromatográfica foi realizada em coluna DB-1, com gradiente de temperatura de 100 a $300{ }^{\circ} \mathrm{C}$, a $8{ }^{\circ} \mathrm{C} / \mathrm{min}$, utilizando He a $1 \mathrm{~mL} / \mathrm{min}$ como gás de arraste. A detecção foi realizada por EM utilizando ionização por impacto de elétrons (IE) ou com ionização química (IQ) com isobutano como gás reagente. Dois fragmentos característicos foram utilizados para quantificação. No estudo foram obtidos limites de detecção de $10 \mathrm{ng}$, para IE, e 20 ng, para IQ, de glifosato em soluções padrão.

Metodologia similar para derivação de glifosato e AMPA foi feita com reação a $100^{\circ} \mathrm{C}$, por $10 \mathrm{~min}$ e $60 \mathrm{~min}$, respectivamente ${ }^{38}$. No entanto, utilizaram outro tipo de coluna, de menor comprimento, operada a $200{ }^{\circ} \mathrm{C}$ para glifosato e $170{ }^{\circ} \mathrm{C}$ para AMPA, com nitrogênio como gás de arraste. Para a detecção combinaram FC e EM, o que garantiu boa sensibilidade e seletividade do método. Alferness e Iwata $^{7}$, entretanto, realizaram derivação com heptafluorobutanol e TFAA, seguida da análise cromatográfica. A programação de temperatura foi de 90 até $290^{\circ} \mathrm{C}$ a $30^{\circ} \mathrm{C} / \mathrm{min}$, usando He como gás de arraste. A detecção foi feita por EM, selecionando dois íons característicos para glifosato e AMPA. Recuperações de 90 a $100 \%$ e 89 a $103 \%$ foram obtidas para o herbicida e seu produto de degradação, respectivamente, com limite de detecção de $0,01 \mathrm{mg} / \mathrm{Kg}$.

Outra reação de derivação foi feita com TFAA e TFE ${ }^{21}$. Amostras de água previamente tratadas em colunas de troca iônica, foram concentradas e retomadas com os reagentes de derivação. A reação foi feita por $1 \mathrm{~h}$ a $100^{\circ} \mathrm{C}$. Após evaporação e redissolução em acetato de etila, os extratos contendo os derivados de glifosato e AMPA foram analisados por CG/EM, ambos identificados por três íons característicos. Boa linearidade foi obtida para o pesticida e seu metabólito (0,1 a 2,5 mg/L), embora baixos limites de detecção e quantificação tenham sido obtidos $(0,05$ e $0,1 \mathrm{mg} / \mathrm{L})$. As recuperações variaram de 58 a $91 \%$ para glifosato em solo, com coeficientes de variação de $23 \%$.

\section{Determinação por cromatografia gasosa com detecção por fotometria em chama}

Tsuji e colaboradores ${ }^{39}$ puderam determinar glifosato em grãos, utilizando CG após derivação com trimetilortoacetato a $80{ }^{\circ} \mathrm{C}$ por $1,5 \mathrm{~h}$. Antes da análise propriamente dita, foi necessária uma etapa de purificação. A análise cromatográfica foi feita com programação de temperatura de $50{ }^{\circ} \mathrm{C}$ até $250^{\circ} \mathrm{C}$, utilizando hélio como gás de 
Tabela 3. Determinação de glifosato e AMPA por CG

\begin{tabular}{|c|c|c|c|c|}
\hline Amostra & Derivação & Condições analíticas & Detecção & Ref. \\
\hline Soluções padrão & $\begin{array}{l}\text { N-metil-N-(t-butildimetilsilil)- } \\
\text { trifluoroacetamida }\end{array}$ & $\begin{array}{l}\text { Coluna: DB-1 } \\
\text { Temp.: } 100-300^{\circ} \mathrm{C}\left(8^{\circ} \mathrm{C} / \mathrm{min}\right) \\
\text { Gás de arraste: } \mathrm{He}\end{array}$ & EM usando IE ou IQ & 37 \\
\hline Soluções padrão & $\begin{array}{l}\text { N-metil-N-(t-butildimetilsilil)- } \\
\text { trifluoroacetamida }\end{array}$ & $\begin{array}{l}\text { Temp.: } 170-200^{\circ} \mathrm{C} \\
\text { Gás de arraste: } \mathrm{N}_{2}\end{array}$ & FC e EM & 38 \\
\hline Solo & Heptafluorobutanol e TFAA & $\begin{array}{l}\text { Temp.: } 90-290^{\circ} \mathrm{C}\left(30^{\circ} \mathrm{C} / \mathrm{min}\right) \\
\text { Gás de arraste: } \mathrm{He}\end{array}$ & EM & 7 \\
\hline Água & TFAA e TFE & & EM & 21 \\
\hline Vegetais & trimetilortoacetato & $\begin{array}{l}\text { Temp.: } 50-250^{\circ} \mathrm{C} \\
\text { Gás de arraste: } \mathrm{He}\end{array}$ & FC & 39 \\
\hline Soluções padrão & Trifluoroetanol e pentafluoropropanol & $\begin{array}{l}\text { Temp.: } 150^{\circ} \mathrm{C} \\
\text { Gás de arraste: } \mathrm{N}_{2}\end{array}$ & FC (modo P) e DCE & 40 \\
\hline Água Solo Raízes & $\begin{array}{l}\text { Cloroformiato de isopropila e } \\
\text { diazometano }\end{array}$ & $\begin{array}{l}\text { Temp.: } 170-270^{\circ} \mathrm{C}\left(10^{\circ} \mathrm{C} / \mathrm{min}\right) \\
\text { Gás de arraste: } \mathrm{N}_{2}\end{array}$ & $\mathrm{FC}$ & 41 \\
\hline Vegetais & Anidrido trifluoroacético e diazometano & Temp.: $110-175^{\circ} \mathrm{C}\left(10^{\circ} \mathrm{C} / \mathrm{min}\right)$ & $\mathrm{FC}$ & 42 \\
\hline Solo & Anidrido trifluoroacético e TFE & & DCE & 8 \\
\hline Água potável & Anidrido trifluoroacético e TFE & & DNP & 43 \\
\hline Água Solo & $\mathrm{N}$-isobutoxicarbonilmetilester & $\begin{array}{l}\text { Temp.: } 170-270^{\circ} \mathrm{C}\left(10^{\circ} \mathrm{C} / \mathrm{min}\right) \\
\text { Gás de arraste: } \mathrm{N}_{2}\end{array}$ & FC/EM & 44 \\
\hline Sangue & Pirólise $\left(\mathrm{Cr}-\mathrm{Na}_{2} \mathrm{CO}_{3}\right)$ & $\begin{array}{l}\text { Coluna com } 50 \% \text { de PEG } 20 \mathrm{M} \\
\text { Temp.: } 50^{\circ} \mathrm{C} \\
\text { Gás de arraste: } \mathrm{N}_{2}\end{array}$ & DIC & 45 \\
\hline
\end{tabular}

arraste e detecção por FC. Recuperações superiores a $70 \%$ foram observadas. Os limites de detecção foram de $0,02 \mathrm{mg} / \mathrm{Kg}$.

A derivação com TFE ou pentafluoropropanol e anidrido trifluoroacético ou heptafluorobutírico apresentaram boa sensibilidade $^{40}$. Após a derivação, a separação e análise foram feitas em coluna cromatográfica operada a $150{ }^{\circ} \mathrm{C}$, com nitrogênio como gás de arraste, a 27,6 $\mathrm{mL} / \mathrm{min}$. Utilizaram como detectores o fotométrico de chama (no modo P) ou o de captura de elétrons, DCE.

Melhor sensibilidade foi, ainda, obtida por Kataoka e colaboradores $^{41}$ que derivaram o glifosato com cloroformiato de isopropila e diazometano, analisando por CG, com programação de temperatura de 170 até $270{ }^{\circ} \mathrm{C} \mathrm{a} 10^{\circ} \mathrm{C} / \mathrm{min}$, usando nitrogênio como gás de arraste a $10 \mathrm{~mL} / \mathrm{min}$ e obtendo limites de detecção de 8 a $20 \mathrm{pg}$.

Seiber e colaboradores ${ }^{42}$ utilizaram derivação com anidrido trifluoroacético e diazometano, com prévia separação por cromatografia líquida e eluição em gradiente de t-butilmetileter e tetrahidrofurano e detecção a $220 \mathrm{~nm}$. Após a separação por CLAE, foi feita a análise por CG, utilizando coluna específica, operada com programação de temperatura de $110{ }^{\circ} \mathrm{C}$ até $175^{\circ} \mathrm{C}$, a $10{ }^{\circ} \mathrm{C} / \mathrm{min}$ e detecção por FC. Recuperações de $87 \%$ foram obtidas para alimentos fortificados em concentrações variando de 0,1 a $0,25 \mu \mathrm{g} / \mathrm{g}$ de glifosato.

A prévia derivação com anidrido trifluoroacético e trifluoroetanol

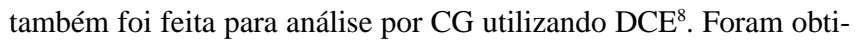
das recuperações de 88 a 104\% para o herbicida. Ainda com os mesmos reagentes sendo usados na derivação, a análise por CG usando detector de nitrogênio e fósforo (DNP) forneceu recuperações de $75 \%$ para glifosato e $80 \%$ para AMPA com limite de detecção em torno de $0,01 \mu \mathrm{g} / \mathrm{g}^{43}$.

Realizando derivação com $\mathrm{N}$-isobutoxicarbonilmetilester, seguida de análise cromatográfica, Kataoka e colaboradores ${ }^{44}$ utilizaram a detecção por fotometria em chama, confirmando as estruturas por espectrometria de massas. A análise apresentou relação linear para concentrações entre 5 e 200 ng e recuperações de 96,2 a 100,3\%, para amostras de água, e 81,7 a 99,1\% para amostras de solo. Limites de detecção de 10 e 15 pg para glifosato e AMPA, respectivamente, foram obtidos.

A pirólise a $590{ }^{\circ} \mathrm{C}$, durante intervalo de $4 \mathrm{~s}$, após adição de $\mathrm{Cr}$ $\mathrm{Na}_{2} \mathrm{CO}_{3}$ (2:1), foi inicialmente feita, seguida por análise cromatográfica em coluna com $10 \%$ de PEG $20 \mathrm{M}$, operada a $50{ }^{\circ} \mathrm{C}$, com nitrogênio como gás de arraste e detecção por ionização em chama (DIC), obtendo recuperações de 98 a $102 \%{ }^{45}$.

\section{Outras técnicas}

Métodos baseados em outras técnicas, além das cromatográficas, vêm sendo desenvolvidos para a determinação de glifosato e seu metabólito, embora ainda sejam pouco utilizados. Estas técnicas incluem ressonância magnética nuclear de fósforo $31\left(\mathrm{RMN}{ }^{31} \mathrm{P}\right)$, pouco convencional, espectrofotometria, polarografia e eletroforese.

\section{Determinação por $R M N{ }^{31} P$}

Amostras dissolvidas em $\mathrm{D}_{2} \mathrm{O}(0,5 \mathrm{~mL})$ foram analisadas por ressonância magnética nuclear de ${ }^{31} \mathrm{P}$, em frequiência de $81 \mathrm{MHz}$, obtendo-se o espectro em 1 min. As recuperações não foram reportadas ${ }^{46}$.

\section{Determinação por espectrofotometria}

Segundo Dong e colaboradores ${ }^{47}$, é possível determinar glifosato em águas residuárias, utilizando método espectrofotométrico. Amos- 
tras são diluídas com água destilada, seguida de reações com EDTA dissódico, nitrito de sódio e ácido sulfúrico, e depois com iodeto de potássio e amido, toda a reação ocorrendo a $15^{\circ} \mathrm{C}$. A absorvância foi medida em $550 \mathrm{~nm}$, com linearidade entre 0,375 e 4,5 mg/L e recuperações de 95 a 104\%. É importante ressaltar que é necessário um sistema com temperatura controlada, pois a reação do iodo com amido produz composto colorido, que têm diminuição de absorvância com o aumento de temperatura. Zhemchuzhin e Gorobets ${ }^{48}$ também descrevem um método espectrofotométrico, neste caso, usando reação com água de bromo na presença de tampão acetato para formação de brometo do herbicida, e depois tampão pirofosfato, solução de álcooldehidrogenase e $\mathrm{NAD}^{+}$, em etanol aquoso a $50 \%$. A determinação foi realizada a $340 \mathrm{~nm}$, observando-se a diminuição da atividade enzimática.

\section{Determinação por polarografia}

Tanto amostras de solo quanto de água, após extração, purificação e pré-concentração, foram analisadas por polarografia para determinação de glifosato, tratando-se a amostra acidificada com carvão ativado, seguida de nitração de uma alíquota da amostra ${ }^{6}$. Um volume da amostra que não sofreu nitração foi colocada na célula polarográfica, sofrendo remoção do oxigênio por passagem de $\mathrm{N}_{2}$. A medida foi iniciada depois de estabilizada a corrente inicial em $-0,5 \mathrm{~V}$, variando-se 2 $\mathrm{mV} / \mathrm{s}$ na direção negativa, com pulso em amplitude de $100 \mathrm{mV}$ e tempo de gota de $2 \mathrm{~s}$. O procedimento foi repetido com a amostra que sofreu a nitração. As recuperações foram de 63 a $89 \%$ para solo e 67 a $81 \%$ para água, tendo como limite de detecção 0,5 a $1,0 \mu \mathrm{g} / \mathrm{g}$.

\section{Determinação por eletroforese}

Amostras de soro sanguíneo foram desproteinizadas com ácido tricloroacético, centrifugadas e derivadas com cloreto de $p$-toluenosulfonila na presença de tampão fosfato $(\mathrm{pH} 11)$, sendo analisadas por eletroforese em coluna capilar de sílica fundida $(72 \mathrm{~cm}$ x $50 \mu \mathrm{m})$ operada a $35^{\circ} \mathrm{C}$ e $30 \mathrm{kV}$. Foi utilizado tampão borato (pH de 8,7 a 9,6 ) contendo $10 \%$ de metanol e detecção a $240 \mathrm{~nm}$. A calibração mostrou linearidade para valores de 0,5 a $100 \mathrm{mg} / \mathrm{L}$ de glifosato e $\mathrm{AMPA}^{49}$.

Alferness e Iwata ${ }^{7}$ desenvolveram um método de eletroforese com uma coluna capilar $(64,5 \mathrm{~cm}$ x $50 \mu \mathrm{m})$ operada a $25^{\circ} \mathrm{C}$, com eletrólito de hidrogenoftalato de potássio ajustado a $\mathrm{pH} 7,5 \mathrm{e}$ $0,5 \mathrm{mmol} \mathrm{L}^{-1}$ de brometo de tetradeciltrimetilamônio, aplicando $27,6 \mathrm{kV}$ e detectando a $240 \mathrm{~nm}$. Este método foi aplicado a amostras de solo, água, tecidos animais e vegetais. Para água foram obtidas as recuperações de $95-97 \%\left(0,2 \mu \mathrm{g} \mathrm{L}^{-1}\right), 99-112 \%\left(10 \mu \mathrm{g} \mathrm{L}^{-1}\right), 99-105 \%$ $\left(100 \mu \mathrm{g} \mathrm{L}^{-1}\right)$, enquanto que para solo obtiveram recuperações de $84 \mathrm{a}$ $97 \%$ para amostras com níveis de fortificação de 0,05 a $0,50 \mathrm{mg} / \mathrm{kg}$.

\section{CONCLUSÕES}

O glifosato apresenta características muito específicas, o que dificulta seu monitoramento em solo e água, sua determinação é de grande relevância devido à sua ampla utilização. A extração em amostras de solo tem sido realizada principalmente com reações ácidobase, sendo extremamente afetada pelas propriedades e composição do solo. Bases fracas orgânicas, como trietilamina, são eficazes apenas para extração do composto livre, não sendo capaz de extrair o composto adsorvido. Solos com maior teor de matéria orgânica apresentaram melhores recuperações, enquanto os minerais e argilosos apresentam recuperações inferiores devido à interação com os sítios iônicos do solo. Em amostras de água, podem ser efetuadas extrações em fase sólida (EFS) usando-se resinas de troca iônica, sendo possível realizar a análise por simples filtração e evaporação da amostra. Uma outra metodologia é a derivação, onde se obtém compostos apolares que podem ser extraídos com solventes orgânicos. Esta derivação pode diminuir a recuperação do composto, uma vez que envolve o uso de maior número de etapas. Os estudos realizados para estes compostos, em geral, não avaliam a eficácia do processo de extração, apresentando recuperações relacionadas ao processo analítico completo, desde a extração até a detecção. Deste modo, tornase difícil comparar as recuperações no sentido de avaliar qual o melhor procedimento de extração para o herbicida e seu produto de degradação.

A técnica mais utilizada para a determinação de glifosato é a cromatografia líquida de alta eficiência (CLAE), necessitando, entretanto de derivação para produção de compostos que interajam com radiação eletromagnética, aplicando-se, assim, detecção colorimétrica, por UV ou detecção fluorimétrica. Comparando com outros métodos de detecção, a determinação por absorção no UV-VIS apresenta como vantagens a simplicidade, bem como menores coeficientes de variação, recuperações e limites de detecção adequados.

A cromatografia gasosa (CG) apresenta a vantagem de possuir elevada sensibilidade, porém, exige derivação para obtenção de compostos voláteis. Pode-se, ainda, adicionar a especificidade da espectrometria de massas às técnicas cromatográficas, tanto líquida quanto gasosa.

Outras técnicas têm sido aplicadas na análise do herbicida, o que favorece o seu estudo. Entre elas, destacam-se a polarografia, a eletroforese capilar, a espectrofotometria e a ressonância magnética nuclear, evidenciando a possibilidade de determinação por outras técnicas menos convencionais para a análise de resíduos de pesticidas, podendo ser adequadamente aplicadas como alternativas de análise do composto em amostras ambientais.

\section{REFERÊNCIAS}

1. http://www.gn.apc.org/pesticidestrust/aifacts/glyphosa.htm, acessada em Fevereiro 2000.

2. Carlisle, S. M.; Trevors, J.T.; Water, Air, Soil Pollut. 1988, 39, 409.

3. Thompson, D.G.; Cowell, J.E.; Daniels, R. J.; Staznik, B.; MacDonald, L. M.; J. AOAC Int. 1989, 72, 355.

4. Aubin, A. J.; Smith, A. E.; J. Agric. Food Chem. 1992, 40, 1163.

5. Sancho, J. V.; Hidalgo, C.; Hernandez, F. Lopez, F. J.; Hogendoorn, E. A.; Dijkman, E.; Int. J. Environ. Anal. Chem. 1996, 62, 53.

6. Friestad, H. O.; Broenstad, J. O.; J. AOAC Int. 1985, 68, 76.

7. Alferness, P. L.; Iwata, Y.; J. Agric. Food. Chem. 1994, 42, 2751.

8. Eberbach, P. L.; Douglas, L. A.; J. Agric. Food. Chem. 1991, 39, 1776.

9. Lundgren, L. N.; J. Agric. Food. Chem. 1986, 34, 353.

10. Miles, C.J.; Moye, H. A.; J. Agric. Food. Chem. 1988, 36, 486.

11. Miles, C. J.; Wallace, L. R.; Moye, H. A.; J. AOAC Int. 1986, 69, 458.

12. Cowell, J. E.; Kunstman, J. L.; Nord, P. L.; Steinmetz, J. R.; Wilson, G. R.; J. Agric. Food. Chem. 1986, 34, 955.

13. Wigfield, Y. Y.; Lanouette, M.; Anal. Chim. Acta 1990, 233, 311.

14. Abdullah, M. P.; Daud, J.; Hong, K. S.; Yew, C. H.; J. Chromatogr. A 1995, $697,363$.

15. Shevchuck, I. A.; Dubchenko, Yug.; Grudneva, G. E.; Zh. Anal. Khim. 1987, $42,328$.

16. Reupert, R.; Fuchs, S.; Git. Fachz. Lab. 1997, 41, 468.

17. Gauch, R.; Leuenberger, U.; Mueller, U.; Z. Lebensm. Unters. Forsch. 1989 , $188,36$.

18. Vreeken, R. J.; Speksmijder, P.; Bodeldijik-Pastorava, I.; Noij, Th, H. M.; J. Chromatogr. A 1998, 794, 187.

19. Avramov, Y. U. B.; Vasileu, K. R.; Zh. Anal. Khim. 1992, 47, 388

20. Oppenhuizen, M. E.; Cowell, J. E.; J. AOAC Int. 1991, 74, 317.

21. Börjesson, E.; Torstensson, L.; J. Chromatogr. A 2000, 886, 207.

22. Sem, N. P.; Baddoo, P. A.; Int. J. Environ. Anal. Chem. 1996, 63, 107.

23. Miles, C. J.; Leong, G.; CL-CG North Am. 1992, 10, 452.

24. Burns, A. J.; J. AOAC Int. 1983, 66, 1214.

25. Morlier, L. W.; Tomkins, D. F.; J. AOAC Int. 1997, 80, 464.

26. Morovjan, G.; Fekete, J.; Repasi, J.; J. Liq. Chromatogr. 1995, 18, 3219.

27. Powell, H. A.; Kerby, N. W.; Rowell, P.; J. Chromatogr. 1990, 502, 201. 
28. Huber Iii, J. W.; Calabrese, K. L.; CL-Mag. 1985, 3, 888

29. Lundgren, L. N.; J. Agric. Food. Chem. 1986, 34, 353.

30. Tuinstra, L. G. M. T.; Kienhuis, P. G. M.; Chromatographia 1987, 24, 696.

31. Reupert, R.; Fuchs, S.; Git. Fachz. Lab. 1997, 41, 468.

32. Kawai, S.; Uno, B.; Tomita, M. J.; J. Chromatogr. 1991, 540, 411.

33. Loudahl, M.J.; Pietrzyk, D. J.; J. Chromatogr. 1992, 602, 197.

34. Bauer, K. H.; Knepper, T. P.; J. Chromatogr. A 1999, 837, 117.

35. Ridlen, J.S.; Klopf, G.J.; Nieman, T. A.; Anal. Chim. Acta 1997, 341, 195.

36. Bunyatyan, Y. U. A.; Gevorgyan, A.; A. Gig. Sanit. 1984, 5, 43.

37. Tsunoda, N.; J. Chromatogr. 1993, 637, 167.

38. Moyle, H. A.; Deyrup, C. L.; J. Agric. Food. Chem. 1984, 32, 192.

39. Tsuji, M.; Akiyama, Y.; Yano, M.; Anal. Sci. 1997, 13, 283.

40. Deyrup, C. L.; Chang, S. M.; Weintraub, R. A.; Moye, H. A.; J. Agric. Food. Chem. 1985, 33, 944.
41. Kataoka, H.; Ryu, S.; Sakiyama, N. Makita, M.; J. Chromatogr. A 1996, $726,253$.

42. Seiber, J. N.; Mcchesney, M. M.; Kon, R.; Leavitt, R.A.; J. Agric. Food. Chem. 1984, 32, 678.

43. Roy, D. N.; Konor, S. K.; J. Agric. Food. Chem. 1989, 37, 441.

44. Kataoka, H.; Horii, K.; Makita, M.; Biosci. Biotech. Biochem. 1991, 55 , 195.

45. Hilda, M.; Mitsui, T.; Fujimura, Y.; Bunseki. Kagaku. 1989, $38,87$.

46. Dickson, S. J.; Meinhold, R. H.; Beer, I. D.; Koelmeyer, T.D.; J. Anal. Toxicol. 1988, 12, 284.

47. Dong, W. H.; Chen, X. C.; Lang, Z. M.; Fan, Y. X.; Liu, J.; Lihua. Jianyan., Huaxue. Fence. 1997, 33, 347.

48. Zhemchuzhin, S. G.; Gorobets, R. P.; Zh. Anal. Khim. 1989, 44, 741.

49. Tomita, M.; Okuyama, T.; Watanabe, S.; Uno, B.; Kawai, S.; J. Chromatogr. Biomed. Appl. 1991, 1-2, 324. 